\title{
Failure curves for predicting brittle fracture in V-notched structural components loaded under mixed tension/shear: An advanced engineering design package
}

\author{
A.R. Torabi*
}

Fracture Research Laboratory, Faculty of New Science and Technologies, University of Tehran, P.O. Box 13741-4395, Tehran, Iran

\begin{tabular}{|c|c|}
\hline $\begin{array}{l}\text { ARTICLE INFO } \\
\end{array}$ & AB S T RACT \\
\hline $\begin{array}{l}\text { Article history: } \\
\text { Received March 20, } 2013 \\
\text { Received in Revised form } \\
\text { August, 21, } 2013 \\
\text { Accepted } 21 \text { August } 2013 \\
\text { Available online } \\
\text { 21 August } 2013 \\
\text { Keywords: } \\
\text { Failure curve } \\
\text { Brittle fracture } \\
\text { V-notch } \\
\text { Load-bearing capacity } \\
\text { Design package } \\
\text { Mixed mode loading }\end{array}$ & $\begin{array}{l}\text { Numerous failure curves are presented in this manuscript to predict the onset of sudden fracture } \\
\text { in V-notched brittle materials under combined tension-shear loading conditions. The curves } \\
\text { were developed in a computational manner in terms of the notch stress intensity factors and } \\
\text { based on the suitable failure concept of the maximum tangential stress (MTS) utilized } \\
\text { frequently in the past by the author and his co-researchers for predicting mixed mode brittle } \\
\text { fracture in extensive notched specimens. Three extensively used notch angles and various notch } \\
\text { tip radii were considered in the computations. A wide range of brittle materials were also taken } \\
\text { into account by defining and using the material critical distance. Through predicting load- } \\
\text { bearing capacity and notch bifurcation angle utilizing only the two basic material properties } \\
\text { namely the ultimate tensile strength and the plane-strain fracture toughness, engineers can } \\
\text { design more rapidly and conveniently the V-notched brittle components with the aim to } \\
\text { withstand reliably against sudden fracture. }\end{array}$ \\
\hline
\end{tabular}

\section{Introduction}

Design plays a vital role in safe and reliable operation of engineering components and structures. Despite general objectives exist in all kinds of mechanical design; the main goal is certainly to prevent failure in components with an appropriate factor of safety. For this purpose, several failure criteria has been proposed and utilized regarding different material and structural failures such as yielding, tearing, brittle fracture, fatigue fracture, creep rupture, buckling etc.

An important branch of mechanical engineering, namely the fracture mechanics, is focused on the design and analysis of the elements containing stress concentrators like cracks, flaws, scratches and notches. Such elements can fail in different manners depending on the material properties and the type of the loads applied. Since fracture occurs suddenly in brittle and quasi-brittle components and

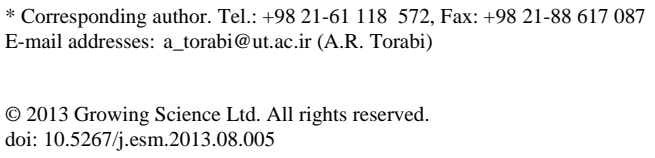


structures, the main attention in fracture mechanics is paid to the brittle fracture as a catastrophic failure.

Unlike cracks and flaws which in the most cases are unfavorable to appear in engineering elements, notches, especially V-shaped ones, are employed because of some particular design requirements. A $\mathrm{V}$-notch concentrates stresses around its tip and hence can become prone to initiate crack(s). Such cracks can propagate in the notched component and finally lead to fracture. From the fracture mechanics point of view, the mechanisms of crack initiation and propagation from a notch tip are fundamentally different for ductile and brittle materials. For brittle materials, the initiation of crack from the notch tip consumes a great portion of the total fracture energy and the crack propagation is very less contributed in energy consumption. This is because the crack growth is such a rapid and unstable phenomenon that the final fracture occurs suddenly. Conversely, for ductile materials exhibit large plastic deformations around notches, both crack initiation and propagation phases consume considerable amount of energy during ductile rupture.

Various concepts of failure have been suggested in the open literature for predicting brittle fracture in engineering components and structures containing sharp and rounded-tip V-notches. Lazzarin and Zambardi (2002) made use of the equivalent strain energy density approach to predict failure in sharp $\mathrm{V}$-shaped notches under localized and generalized plasticity. The strain energy density concept has also been utilized by the same and the other investigators to predict brittle fracture in V-notched components under in-plane loading conditions (see for example Lazzarin and Zambardi, 2001; Berto and Lazzarin, 2009a; Gomez et al., 2009; Ayatollahi et al., 2011a; Berto and Lazzarin, 2009b; Lazzarin et al., 2009; Berto et al., 2012; Lazzarin et al., 2013). The other failure concept utilized by Berto et al. (2008, 2009) for sharp V-shaped notches is the fictitious notch tip radius. Moreover, several fracture criteria have been developed in the past based on determining a critical value for the notch stress intensity factor, so-called the notch fracture toughness. In this context, one can refer to Seweryn (1994), Gomez and Elices (2003a,b), Leguillon and Yosibash (2003), Gomez and Elices (2004) and Ayatollahi and Torabi (2010a) for pure mode I and Ayatollahi and Torabi (2010b, 2011a,b), Ayatollahi et al. (2011b), Yosibash et al. (2006), Priel et al. (2007) and Torabi (2013) for mixed mode I/II and pure mode II loading conditions.

One of the most important concepts of failure in the context of brittle fracture is the maximum tangential stress (MTS) concept, proposed originally by Erdogan and Sih (1963) for investigating mixed mode brittle fracture in cracked bodies. The MTS concept has been frequently employed by Ayatollahi and Torabi to predict mixed mode brittle fracture in the V-notched Brazilian disc (V-BD) specimens made of PMMA (Ayatollahi \& Torabi, 2010b; Ayatollahi et al., 2011b), polycrystalline graphite (Ayatollahi \& Torabi, 2011a) and soda-lime glass (Ayatollahi \& Torabi, 2011b). The main conclusion obtained from the investigations presented in the four references above was that the MTS model has been a satisfactory failure criterion with a very good accuracy in the context of mixed mode brittle fracture of $\mathrm{V}$-notches.

In this manuscript, extensive failure curves are presented based on the MTS model with the aim to estimate the onset of mixed mode brittle fracture in V-notched components in the entire domain from pure mode I to pure mode II. The curves were developed in a computational manner in terms of the notch stress intensity factors (NSIFs) by using the linear elastic stress distribution around the notch tip. By using such curves, as an advanced engineering design package, one can predict rapidly and more conveniently the mixed mode fracture in $\mathrm{V}$-notched elements made of brittle materials for various notch angles and different notch tip radii.

\section{Elastic stress distribution around a V-notch tip}

Filippi et al. (2002) developed an expression for mixed mode I/II stress distribution around a V-notch shown in Fig. 1. The stress distribution is an approximate formula because it satisfies the boundary conditions only in a finite number of points on the notch edge and not on the entire edge. They 
obtained the stress distribution using a conformal mapping in an auxiliary system of curvilinear coordinates " $U$ and $V$ " that are related to the Cartesian coordinates " $X$ and $\mathrm{Y}^{\text {" as }}(X+i Y)=(U+i V)^{q}$. The power " $q$ " is a real positive coefficient ranging from 1 to 2 .

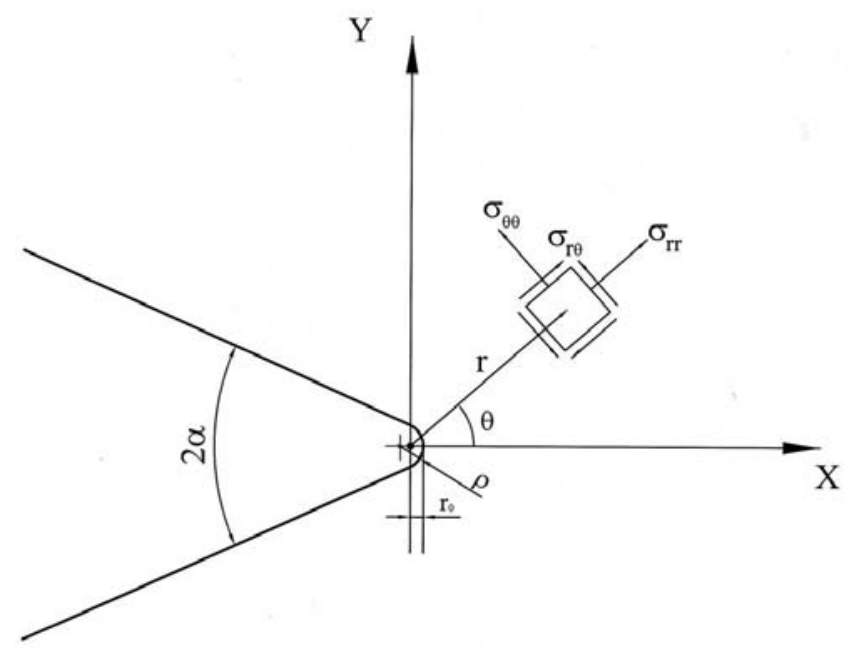

Fig. 1. Round-tip V-notch and its polar coordinate system

The mixed mode I/II stresses can be written as

$$
\left\{\begin{array}{l}
\sigma_{\theta \theta} \\
\sigma_{r r} \\
\sigma_{r \theta}
\end{array}\right\}=\frac{K_{I}^{V, \rho}}{\sqrt{2 \pi} r^{1-\lambda_{1}}}\left[\left\{\begin{array}{c}
f_{\theta \theta}(\theta) \\
f_{r r}(\theta) \\
f_{r \theta}(\theta)
\end{array}\right\}^{(I)}+\left(\frac{r}{r_{0}}\right)^{\mu_{1}-\lambda_{1}}\left\{\begin{array}{l}
g_{\theta \theta}(\theta) \\
g_{r r}(\theta) \\
g_{r \theta}(\theta)
\end{array}\right\}\right]+\frac{K_{I I}^{V, \rho}}{\sqrt{2 \pi} r^{1-\lambda_{2}}}\left[\left\{\begin{array}{c}
f_{\theta \theta}(\theta) \\
f_{r r}(\theta) \\
f_{r \theta}(\theta)
\end{array}\right\}^{(I I)}+\left(\frac{r}{r_{0}}\right)^{\mu_{2}-\lambda_{2}}\left\{\begin{array}{l}
g_{\theta \theta}(\theta) \\
g_{r r}(\theta) \\
g_{r \theta}(\theta)
\end{array}\right\}^{(I I)}\right] \text {, }
$$

where $K_{I}^{V, \rho}$ and $K_{I I}^{V, \rho}$ are the mode I and mode II notch stress intensity factors (NSIFs), respectively. The parameter $r_{0}$ is the distance between the origin of the polar coordinate system and the notch tip. The functions $f_{i j}(\theta)$ and $g_{i j}(\theta)$ have been reported by Ayatollahi and Torabi (2010b) and the eigenvalues $\lambda_{i}$ and $\mu_{i}$ which depend on the notch angle have been reported by Filippi et al. (2002). It can be shown that if the notch tip radius vanishes, Eq. 1 becomes equal to the stress field obtained previously by Williams (1952) for sharp V-notches. According to a relation that exists between the Cartesian and the curvilinear coordinate systems, $r_{0}$ can be written as (Filippi et al., 2002):

$r_{0}=\frac{\pi-2 \alpha}{2(\pi-\alpha)} \rho$

where $2 \alpha$ is the notch angle and $\rho$ is the notch tip radius. The expressions for NSIFs are (Lazzarin \& Filippi, 2006):

$$
\begin{aligned}
K_{I}^{V, \rho}=\sqrt{2 \pi} \frac{\left(\sigma_{\theta \theta}\right)_{\theta=0} r^{1-\lambda_{1}}}{1+\omega_{1}\left(\frac{r}{r_{0}}\right)^{\mu_{1}-\lambda_{1}}}, \\
K_{I I}^{V, \rho}=\sqrt{2 \pi} \frac{\left(\sigma_{r \theta}\right)_{\theta=0} r^{1-\lambda_{2}}}{1+\omega_{2}\left(\frac{r}{r_{0}}\right)^{\mu_{2}-\lambda_{2}}},
\end{aligned}
$$


where $\sigma_{\theta \theta}$ and $\sigma_{r \theta}$ are the tangential and the in-plane shear stresses, respectively. The parameters $\omega_{1}$ and $\omega_{2}$ have been presented by Ayatollahi and Torabi (2010b). If the values of $\omega_{1}$ and $\omega_{2}$ are known, the NSIFs can be obtained from Eq. (3) and Eq. (4) as

$$
\begin{aligned}
K_{I}^{V, \rho} & =\sqrt{2 \pi} \frac{\sigma_{\theta \theta}\left(r_{0}, 0\right) r_{0}{ }^{1-\lambda_{1}}}{1+\omega_{1}}, \\
K_{I I}^{V, \rho} & =\lim _{r \rightarrow r_{0}} \sqrt{2 \pi} \frac{\sigma_{r \theta}(r, 0) r^{1-\lambda_{2}}}{1-\left(\frac{r}{r_{0}}\right)^{\mu_{2}-\lambda_{2}}} .
\end{aligned}
$$

The NSIFs can be calculated for any V-notched component by using the finite element (FE) method as elaborated by Ayatollahi and Torabi (2010b). These parameters have different units of measure (MPa $m^{(1-\lambda 1)}$ and MPa $m^{(1-\lambda 2)}$ for $K_{I}^{V, \rho}$ and $K_{I I}^{V, \rho}$, respectively) and hence, they cannot directly be compared. Note that the parameter $r$ in Eq. 6 cannot be directly substituted by $r_{0}$, because for $r=r_{0}$, $K_{I I}^{V, \rho}$ becomes singular. Therefore, $K_{I I}^{V, \rho}$ is calculated from Eq. 6 at a point very close to the notch tip where $r \rightarrow r_{0}$. When the notch tip radius $\rho$ is zero (i.e. in the case of a sharp notch), the stress values at the notch tip tend to infinity and hence the parameters $K_{I}^{V, \rho}$ and $K_{I I}^{V, \rho}$ cannot be directly obtained by using Eq. (5) and Eq. (6). In such conditions, the limits of the expressions given in Eqs. 5 and 6 must be calculated where $r \rightarrow 0$.

In the next section, the maximum tangential stress (MTS) failure model, frequently utilized by the author and his co-researchers for predicting mixed mode brittle fracture in sharp and rounded-tip Vnotches (see Ayatollahi \& Torabi, 2010b; Ayatollahi et al., 2011b; Ayatollahi \& Torabi, 2011a; Ayatollahi \& Torabi, 2011b), is elaborated. Then, as an engineering design package, comprehensive fracture curves of the MTS model are presented in forthcoming sections for different brittle materials, different notch angles and various notch tip radii.

\section{The MTS model}

The conventional maximum tangential stress (MTS) criterion is a well known failure criterion frequently used for investigating mixed mode brittle fracture for sharp cracks (Erdogan and Sih, 1963). According to this criterion, fracture takes place along the direction of maximum tangential stress $\theta_{0}$ when the tangential stress at the critical distance $r_{c}$ from the crack tip attains a critical value $\left(\sigma_{\theta \theta}\right)_{c}$. The origin of the coordinate system for sharp cracks locates at the crack tip hence the critical distance $r_{c}$ is measured from the crack tip. The material parameters $r_{c}$ and $\left(\sigma_{\theta \theta}\right)_{c}$ are often considered to be independent of geometry and loading conditions for sharp cracks. The results of the MTS and the generalized MTS (Smith et al., 2001) criteria in predicting the fracture initiation in the elements containing a sharp crack have earlier been investigated by several researchers for various brittle materials. A very good agreement has been shown to exist between the theoretical predictions and the experimental results (Erdogan \& Sih, 1963; Ayatollahi \& Aliha, 2008, 2009, 2011; Aliha et al. 2008; Ayatollahi et al., 2011c).

In recent years, the original MTS criterion has been extended to V-notched domains by Torabi and his co-researchers. They developed the sharp and the rounded-tip V-notched MTS fracture criteria namely the SV-MTS (Ayatollahi et al., 2011b) and the RV-MTS (Ayatollahi \& Torabi, 2010b, 2011a,b) for estimating the onset of sudden fracture in V-notched specimens of PMMA, polycrystalline graphite and soda-lime glass. A brief description of the RV-MTS criterion (Ayatollahi \& Torabi, 2010b) is presented herein.

According to the MTS criterion, the first and the second derivatives of the tangential stress $\left(\sigma_{\theta \theta}\right)$ with respect to $\theta$ should be zero and negative, respectively. The first hypothesis of RV-MTS criterion 
suggests that brittle fracture initiates radially from a point on the notch border along a direction for which the tangential stress at a critical distance $r_{c, V}$ is a maximum. The direction $\theta$ corresponding to this point is called the fracture initiation angle $\theta_{0}$. The RV-MTS criterion also proposes that brittle fracture in a V-notched element takes place when the tangential stress $\sigma_{\theta \theta}$ along $\theta_{0}$ and at a critical distance $r_{c, V}$ attains a critical value $\left(\sigma_{\theta \theta}\right)_{c}$. The parameter $r_{c, V}$ is the critical distance for rounded-tip Vnotches measured from the origin of polar coordinate system (Fig. 1) and not from the notch tip. Therefore, $r_{c, V}$ is not a fixed material property and depends on the notch geometry. The parameter $r_{c, V}$ is considered to be independent of mode mixity and thus, it is obtained from critical mode I loading conditions (see for instance Ayatollahi \& Torabi, 2010b; Ayatollahi et al., 2011b; Ayatollahi \& Torabi, 2011a; Ayatollahi and Torabi, 2011b). The notch critical distance for rounded-tip V-notches can be simply taken equal to $r_{c, V}=r_{0}+r_{c}=r_{0}+\frac{1}{2 \pi}\left(\frac{K_{I c}}{\sigma_{c}}\right)^{2}$ as reported by Ayatollahi and Torabi (2010a). The parameter $K_{I c}$ is the plane-strain fracture toughness of material. Note that the distance $r_{0}$ lies outside the material while $r_{c}$ lies on the material. The critical distance $r_{c}=\frac{1}{2 \pi}\left(\frac{K_{I c}}{\sigma_{c}}\right)^{2}$ has also been used by Ayatollahi et al. (2011b) for sharp V-notches and successful prediction of the experimental results has been achieved.

Considering the MTS criterion, one can write:

$\frac{\partial \sigma_{\theta \theta}(r, \theta)}{\partial \theta}=0$,

$\frac{\partial^{2} \sigma_{\theta \theta}(r, \theta)}{\partial \theta^{2}}<0$.

By substituting the tangential component of the stress field from Eq. 1 into Eq. 7a and replacing $r$ and $\theta$ by $r_{c, V}$ and $\theta_{0}$, one can derive an equation for determining the angle $\theta_{0}$ in terms of $K_{I}^{V, \rho}$ and $K_{I I}^{V, \rho}$ as:

$$
\begin{aligned}
& \frac{K_{I}^{V, \rho}}{\sqrt{2 \pi}\left(r_{c, V}\right)^{S}}\left[L\left(-R S \sin S \theta_{0}-R S \chi_{b_{1}} \sin R \theta_{0}\right)+\left(\frac{r_{c, V}}{r_{0}}\right)^{P} M\left(-\chi_{d_{1}} V W \sin W \theta_{0}-\chi_{c_{1}} V \sin V \theta_{0}\right)\right]+ \\
& \frac{K_{I I}^{V, \rho}}{\sqrt{2 \pi}\left(r_{c, V}\right)^{U}}\left[N\left(T U \cos U \theta_{0}+\chi_{b_{2}} T^{2} \cos T \theta_{0}\right)+\left(\frac{r_{c, V}}{r_{0}}\right)^{Q} O\left(\chi_{d_{2}} X Y \cos Y \theta_{0}-\chi_{c_{2}} X \cos X \theta_{0}\right)\right]=0
\end{aligned}
$$

Note that all of the symbols used in Eq. (8) and also in the next equations have been defined and reported by Ayatollahi and Torabi (2010b).

In pure mode I loading condition, $K_{I I}^{V, \rho}$ is zero and Eq. (8) can be rewritten as

$$
L\left(-R S \sin S \theta_{0}-R S \chi_{b_{1}} \sin R \theta_{0}\right)+\left(\frac{r_{c, V}}{r_{0}}\right)^{P} M\left(-\chi_{d_{1}} V W \sin W \theta_{0}-\chi_{c_{1}} V \sin V \theta_{0}\right)=0 .
$$

The trivial root of Eq. 9 is $\theta_{0}=0$. The only acceptable value for $\theta_{0}$ is also zero because of symmetry in geometry and loading conditions. In pure mode II, $K_{I}^{V, \rho}$ is zero and Eq. 8 can be simplified into

$$
N\left(T U \cos U \theta_{0}+\chi_{b_{2}} T^{2} \cos T \theta_{0}\right)+\left(\frac{r_{c, V}}{r_{0}}\right)^{Q} O\left(\chi_{d_{2}} X Y \cos Y \theta_{0}-\chi_{c_{2}} X \cos X \theta_{0}\right)=0
$$


Fracture in pure mode II loading conditions initiates along $\theta_{0}$ (denoted here by $\theta_{\text {OII }}$ ) where the value of $\theta_{\text {OII }}$ is determined by solving Eq. (10). According to Eq. (10), the parameter $\theta_{\text {OII }}$ depends on the notch critical distance $r_{c, V}$, the notch angle and the notch tip radius.

The second hypothesis of the RV-MTS criterion suggests that fracture occurs when the tangential stress along $\theta=\theta_{0}$ and at the distance $r=r_{c, V}$ attains the critical value $\left(\sigma_{\theta \theta}\right)_{c}$. Therefore, at the fracture instance, the tangential stress component of Eq. (1) can be written as:

$$
\begin{aligned}
\left(\sigma_{\theta \theta}\right)_{c}= & \frac{K_{I}^{V, \rho}}{\sqrt{2 \pi}\left(r_{c, V}\right)^{S}}\left[L\left(R \cos S \theta_{0}+\chi_{b_{1}} S \cos R \theta_{0}\right)+\left(\frac{r_{c, V}}{r_{0}}\right)^{P} M\left(\chi_{d_{1}} V \cos W \theta_{0}+\chi_{c_{1}} \cos V \theta_{0}\right)\right]+ \\
& \frac{K_{I I}^{V, \rho}}{\sqrt{2 \pi}\left(r_{c, V}\right)^{U}}\left[N\left(T \sin U \theta_{0}+\chi_{b_{2}} T \sin T \theta_{0}\right)+\left(\frac{r_{c, V}}{r_{0}}\right)^{Q} O\left(\chi_{d_{2}} X \sin Y \theta_{0}-\chi_{c_{2}} \sin X \theta_{0}\right)\right]
\end{aligned}
$$

Eq. (11) is the governing equation of mixed mode brittle fracture in rounded-tip V-shaped notches. On the other hand and from a fracture mechanics point of view, pure mode I fracture takes place when the notch stress intensity factor $\left(K_{I}^{V, \rho}\right)$ reaches its critical value $K_{I c}^{V, \rho}$ (Ayatollahi \& Torabi, 2010a). The parameter $K_{I c}^{V, \rho}$ is called the mode I notch fracture toughness and can be determined experimentally. $K_{I c}^{V, \rho}$ is not a fixed material property because it depends on the notch angle and the notch tip radius. It can also be predicted theoretically by using some appropriate failure criteria like that presented in the Appendix. Such criteria often make use of critical values of tangential stress or strain energy density at a critical distance to derive a relation between $K_{I c}^{V, \rho}$ and material and geometry parameters like tensile strength, $\rho, 2 \alpha$ etc.

If the conditions related to pure mode I fracture

$\theta_{0}=0, K_{I}^{V, \rho}=K_{I c}^{V, \rho}, K_{I I}^{V, \rho}=0$

are replaced into Eq. (11), $\left(\sigma_{\theta \theta}\right)_{c}$ can be written in terms of $K_{I c}^{V, \rho}, r_{c, V}$ and other notch parameters as

$$
\left(\sigma_{\theta \theta}\right)_{c}=\frac{K_{I c}^{V, \rho}}{\sqrt{2 \pi}\left(r_{c, V}\right)^{S}}\left[L\left(R+\chi_{b_{1}} S\right)+H^{P} M\left(\chi_{d_{1}} V+\chi_{c_{1}}\right)\right] .
$$

By replacing Eq. 13 into Eq. 11, $\left(\sigma_{\theta \theta}\right)$ is omitted and an equation can be obtained for the onset of fracture in a rounded-tip V-notched components in terms of $K_{I}^{V, \rho}, K_{I I}^{V, \rho}, K_{I c}^{V, \rho}$ and $r_{c, V}$ as

$$
\begin{aligned}
& K_{I}^{V, \rho}\left[L\left(R \cos S \theta_{0}+\chi_{b_{1}} S \cos R \theta_{0}\right)+(H)^{P} M\left(\chi_{d_{1}} V \cos W \theta_{0}+\chi_{c_{1}} \cos V \theta_{0}\right)\right]+ \\
& K_{I I}^{V, \rho}\left(r_{c, V}\right)^{(S-U)}\left[N\left(T \sin U \theta_{0}+\chi_{b_{2}} T \sin T \theta_{0}\right)+(H)^{Q} O\left(\chi_{d_{2}} X \sin Y \theta_{0}-\chi_{c_{2}} \sin X \theta_{0}\right)\right]= \\
& K_{I c}^{V, \rho}\left[L\left(R+\chi_{b_{1}} S\right)+H^{P} M\left(\chi_{d_{1}} V+\chi_{c_{1}}\right)\right]
\end{aligned}
$$

If the values of $K_{I c}^{V, \rho}$ and $r_{c, V}$ are known for a notched specimen, one can use Eqs. 8 and 14 and plot the mixed mode fracture curves based on the notch stress intensity factors $\left(K_{I}^{V, \rho}\right.$ and $K_{I I}^{V, \rho}$ ) for various notch angles and different notch tip radii. Sample fracture curves are presented in the next sections.

Notice that the parameter $\left(\sigma_{\theta \theta}\right)_{c}$ (i.e. $\sigma_{c}$ ) is a material property and is commonly considered to be the ultimate tensile strength $\sigma_{u}$ for brittle and quasi-brittle materials (see the references above presented by Ayatollahi \& Torabi). 


\section{Fracture curves}

Once the critical distance $r_{c, V}$ is known, mixed-mode brittle fracture in V-notched components can be studied using a series of fracture curves that depend on the notch angle and the notch tip radius. The curves are similar to the fracture curve of the classical MTS criterion frequently used for analyzing the components having a sharp crack. To obtain these curves, a parameter called the notch mode mixity parameter $\left(M_{V}^{e}\right)$ is defined as (Ayatollahi \& Torabi, 2010b):

$M_{V}^{e}=\frac{2}{\pi} \tan ^{-1}\left(\frac{K_{I}^{V, \rho}}{K_{I I}^{V, \rho}} r_{c, V}{ }^{\left(\lambda_{1}-\lambda_{2}\right)}\right)$

The value of $M_{V}^{e}$ varies from zero (for pure mode II) to one (for pure mode I). Now, obtaining the ratio $\left(K_{I}^{V, \rho} / K_{I I}^{V, \rho}\right)$ from Eq. 8 and substituting into Eq. (15) gives

$M_{V}^{e}=\frac{2}{\pi} \tan ^{-1}\left(-\frac{N\left(T U \cos U \theta_{0}+\chi_{b_{2}} T^{2} \cos T \theta_{0}\right)+\left(\frac{r_{c, V}}{r_{0}}\right)^{Q} O\left(\chi_{d_{2}} X Y \cos Y \theta_{0}-\chi_{c_{2}} X \cos X \theta_{0}\right)}{L\left(-R S \sin S \theta_{0}-R S \chi_{b_{1}} \sin R \theta_{0}\right)+\left(\frac{r_{c, V}}{r_{0}}\right)^{P} M\left(-\chi_{d_{1}} V W \sin W \theta_{0}-\chi_{c_{1}} V \sin V \theta_{0}\right)}\right)$

To achieve the fracture curve for given values of the notch tip radius, the notch angle and the notch critical distance, one can follow the steps below respectively:

1- Choose an arbitrary value of the parameter $M_{V}^{e}$ between zero and one.

2- Substitute $M_{V}^{e}$ into Eq. (16).

3- Solve Eq. (16) and determine $\theta_{0}$.

4- Substitute $\theta_{0}$ into Eq. (8) and Eq. (14).

5- Solve a linear system of equations consisting of Eq. (8) and Eq. (14) and find the normalized NSIFs: $\left(K_{I}^{V, \rho} / K_{I c}^{V, \rho}\right)$ and $\left(K_{I I}^{V, \rho} / K_{I c}^{V, \rho}\right)$.

6- Repeat steps 1 to 5 for other values of $M_{V}^{e}$.

7- Draw the fracture curve using the series of points calculated in step 5.

Fig. 2 shows a typical mixed mode (I/II) fracture curve for a V-notched component.

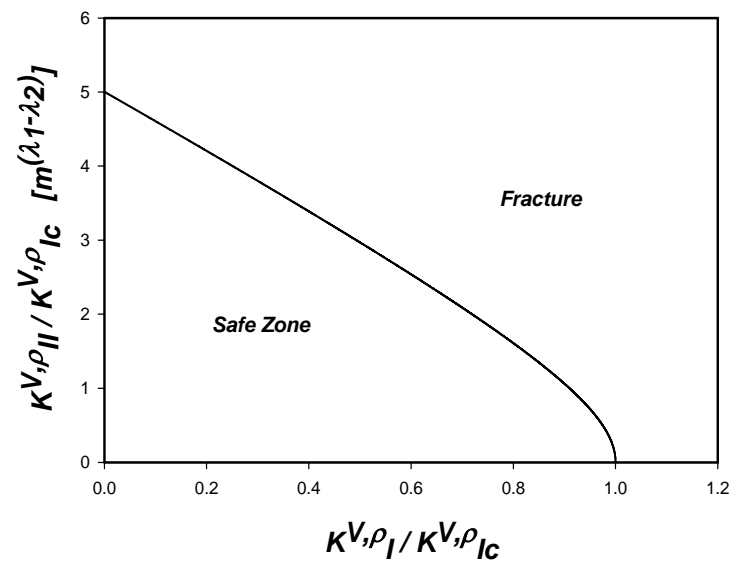

Fig. 2. A typical mixed mode (I/II) fracture curve for a V-notched component 
Note that the parameter $\left(K_{I}^{V, \rho} / K_{I c}^{V, \rho}\right)$ is dimensionless while the parameter $\left(K_{I I}^{V, \rho} / K_{I c}^{V, \rho}\right)$ has a dimension of $\left(m^{\left(\lambda_{1}-\lambda_{2}\right)}\right)$. In order to use these curves in practical cases and to predict if a V-notched brittle component fractures under a given load, first, the notch stress intensity factors (NSIFs) should be calculated for the notched component. These NSIFs are then divided by $K_{I c}^{V, \rho}$ to obtain $\left(K_{I}^{V, \rho} / K_{I c}^{V, \rho}\right)$ and $\left(K_{I I}^{V, \rho} / K_{I c}^{V, \rho}\right)$ and then, the corresponding point is determined in Fig. 2. If the point locates under the fracture curve, the fracture will not occur. But, if it locates over the curve, the fracture is expected to occur. The points locating on the fracture curve represent the onset of mixed mode fracture.

In mechanical design, the main objective for the engineers is to design the notched component in order to withstand against fracture. The procedure to find the load-bearing capacity of a V-notched component under mixed mode loading conditions can be simply explained as follows:

1. Apply a unit load to the FE model of the V-notched component and compute the ratio $\left(K_{I I}^{V, \rho} / K_{I}^{V, \rho}\right)$ for it by using the stress distribution around the V-notch tip (see Eq. (5) and Eq. (6)). Note that the ratio is independent of the magnitude of the load.

2. Draw a line with the slope of $\left(K_{I I}^{V, \rho} / K_{I}^{V, \rho}\right)$ in the plane of fracture curve. The first point of the line is the origin of the coordinate system and the second one is the intersection point between the curve and the line.

3. Read the $\mathrm{x}$ and the $\mathrm{y}$ components of the intersection point (i.e. $\left(K_{I}^{V, \rho} / K_{I c}^{V, \rho}\right)$ and $\left.\left(K_{I I}^{V, \rho} / K_{I c}^{V, \rho}\right)\right)$.

4. Multiply both the obtained components by $K_{I c}^{V, \rho}$ to achieve critical $K_{I}^{V, \rho}$ and $K_{I I}^{V, \rho}$ (the parameter $K_{I c}^{V, \rho}$ can be determined theoretically using appropriate failure criteria like that presented in the Appendix).

5. Increase the initially applied unit load to the greater values till NSIFs reach to the values computed in the step 4. The load associated with the critical NSIFs obtained in this step is, in fact, the loadbearing capacity of the V-notched component.

In addition to the fracture load, the other important parameter in the fracture analysis of V-notched elements is the fracture initiation angle $\left(\theta_{0}\right)$. This parameter plays occasionally an important role in determining the overall damage in notched structures. In order to plot the curves of fracture initiation angle, the following steps should be followed

1- Choose an arbitrary value for $M_{V}^{e}$ between 0 and 1.

2- Substitute $M_{V}^{e}$ into Eq. 16.

3- Solve Eq. 16 and find the fracture initiation angle $\theta_{0}$.

4- Repeat the steps 1 to 3 for other values of $M_{V}^{e}$.

5- Draw the parameter $\theta_{0}$ versus $M_{V}^{e}$.

Fig. 3 represents a typical curve of the fracture initiation angle for a V-notched component. 


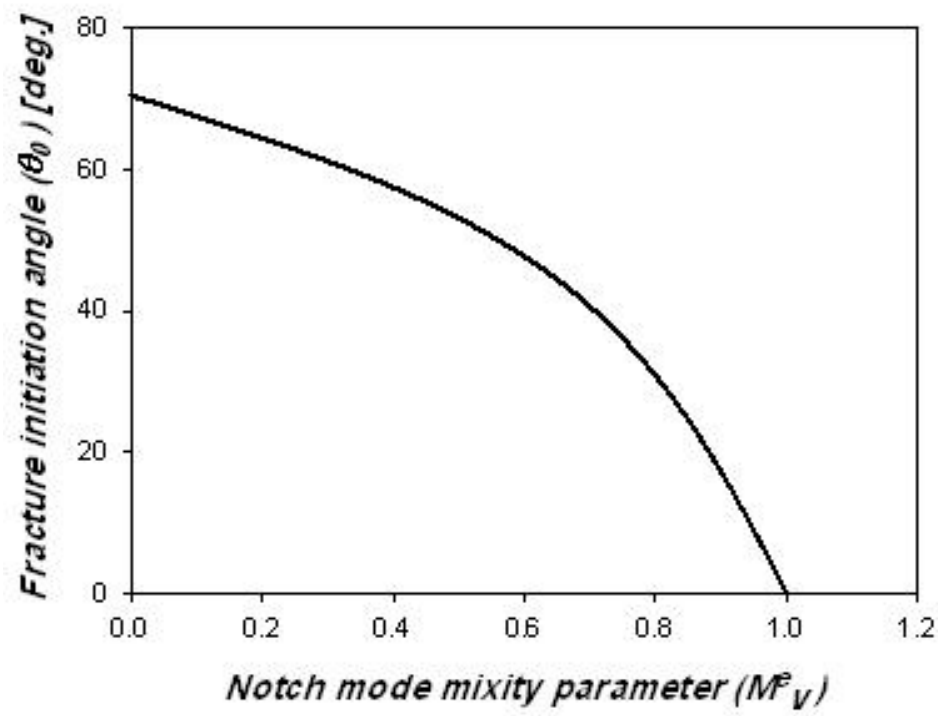

Fig. 3. A typical curve of the fracture initiation angle for a V-notched component

The guideline to determine the fracture initiation angle for a V-notched element subjected to mixed mode loading can be presented as follows:

1. Calculate the ratio $\left(K_{I}^{V, \rho} / K_{I I}^{V, \rho}\right)$ for the notched element by using the stress analysis around the notch tip.

\section{Compute $M_{V}^{e}$ from Eq. 15 .}

3. Find $\theta_{0}$ corresponding to the computed $M_{V}^{e}$ from the curve of fracture initiation angle.

It should be noted that by taking into consideration the notch coordinate system shown in Fig. 1, the sign of the fracture initiation angles $\left(\theta_{0}\right)$ and the mode II NSIFs $\left(K_{I I}^{V, \rho}\right)$ are negative, but the absolute values are shown in Fig. 2 and also in the forthcoming figures.

In the next section, extensive failure curves are presented as a convenient design package to predict brittle fracture in V-notched components under mixed mode I/II loading. The curves depend highly on the values of the notch critical distance $r_{c, V}$, the notch angle and the notch tip radius.

\section{Results and discussion}

One of the most important parameters for engineers in designing the mechanical elements is the availability of a reliable, convenient and relatively rapid design package. The aim of the present work was to prepare a design package for the engineers dealing with mixed mode fracture in mechanical components and structures made of brittle materials and containing a V-shaped notch.

The package consists of numerous failure curves as well as the curves of fracture initiation angle obtained on the basis of the MTS criterion as elaborated in the above sections. The notch angles and the notch tip radii included were $2 \alpha=30,60$ and $90^{\circ}$ and $\rho=0,0.01,0.1,0.3,0.5,1,3,5$ and 10 (mm). The generality of the curves was taken into account by considering different values of the $r_{c}$ parameter (i.e. $\left.\frac{1}{2 \pi}\left(\frac{K_{I c}}{\sigma_{c}}\right)^{2}\right)$ regarding to various brittle materials. The values of $r_{c}$ were $0.01,0.03$, 0.05, $0.1,0.5$ and $1(\mathrm{~mm})$. Total number of 324 curves (162 for the fracture curves and 162 for the curves of fracture initiation angle) were prepared. 
Figs. 4 to 12 display the mixed mode failure curves for $\rho=0,0.01,0.1,0.3,0.5,1,3,5$ and $10 \mathrm{~mm}$, respectively. Each figure consists of several curves related to different values of the notch angle and the critical distance $r_{c}$. The left and the right columns in the figures correspond to the fracture curves and the curves of fracture initiation angle, respectively.
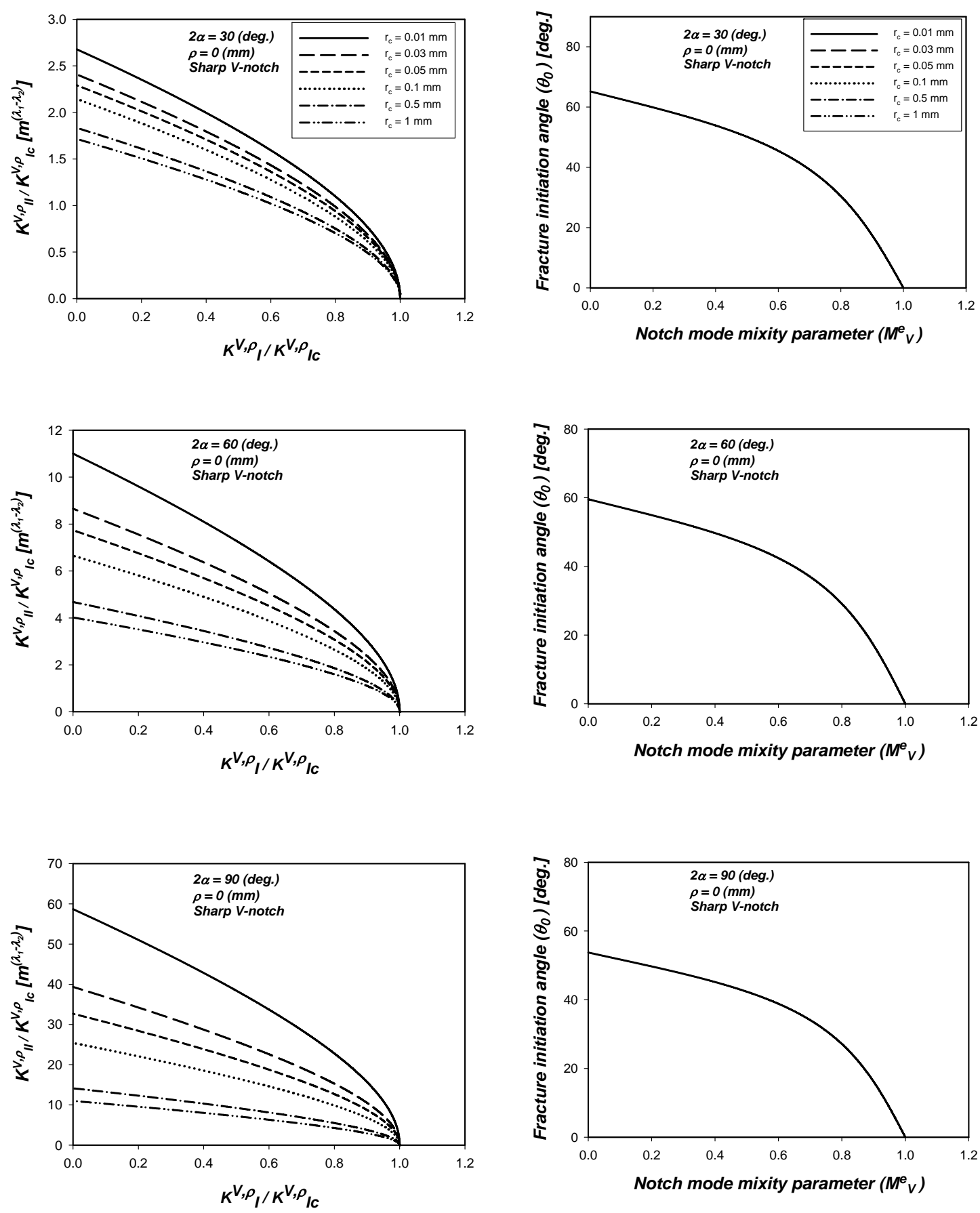

Fig. 4. Mixed mode failure curves for $\rho=0 \mathrm{~mm}$ (sharp V-notches). The left and the right columns correspond to the fracture curves and the curves of fracture initiation angle, respectively 

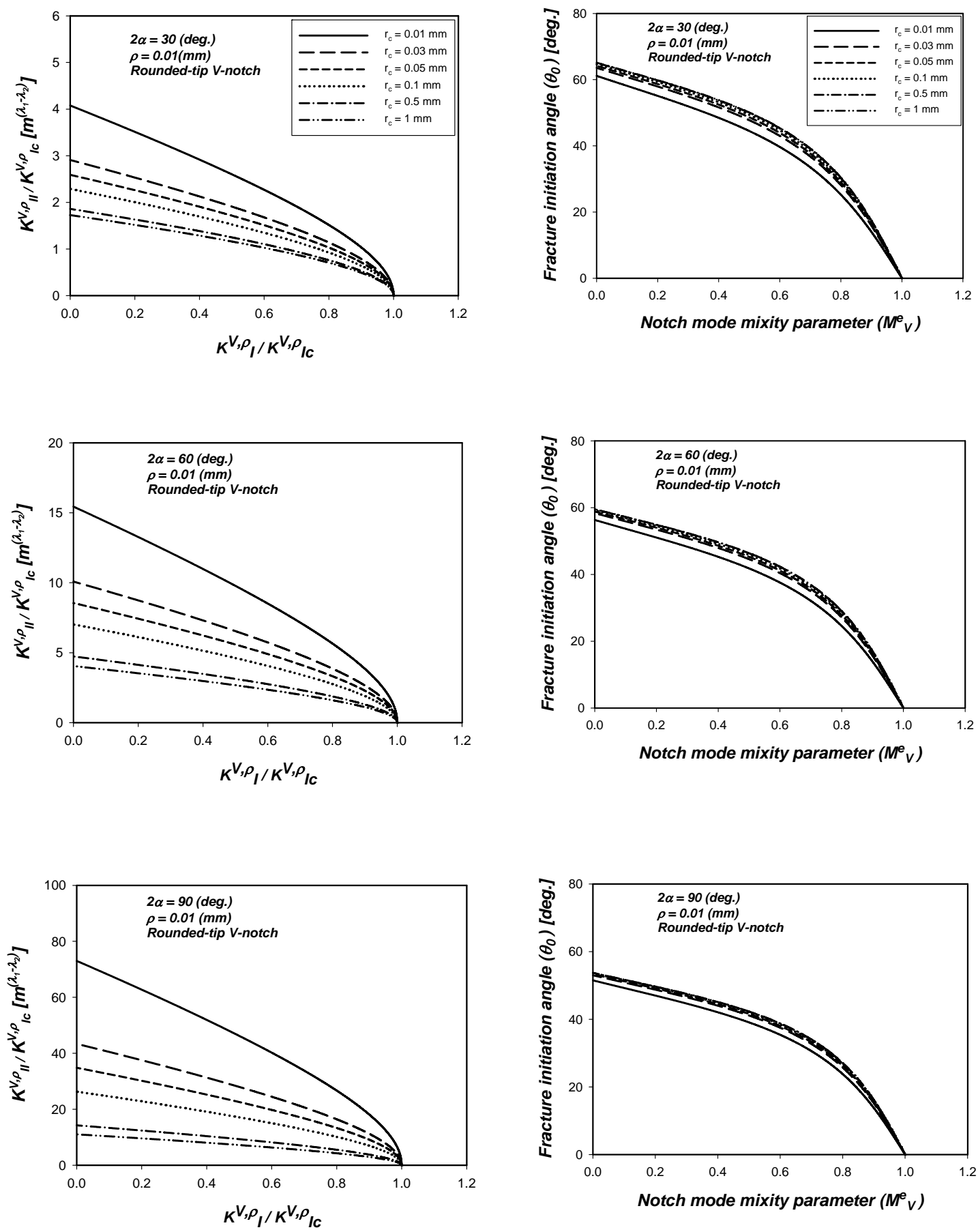

Fig. 5. Mixed mode failure curves for $\rho=0.01 \mathrm{~mm}$. The left and the right columns correspond to the fracture curves and the curves of fracture initiation angle, respectively 

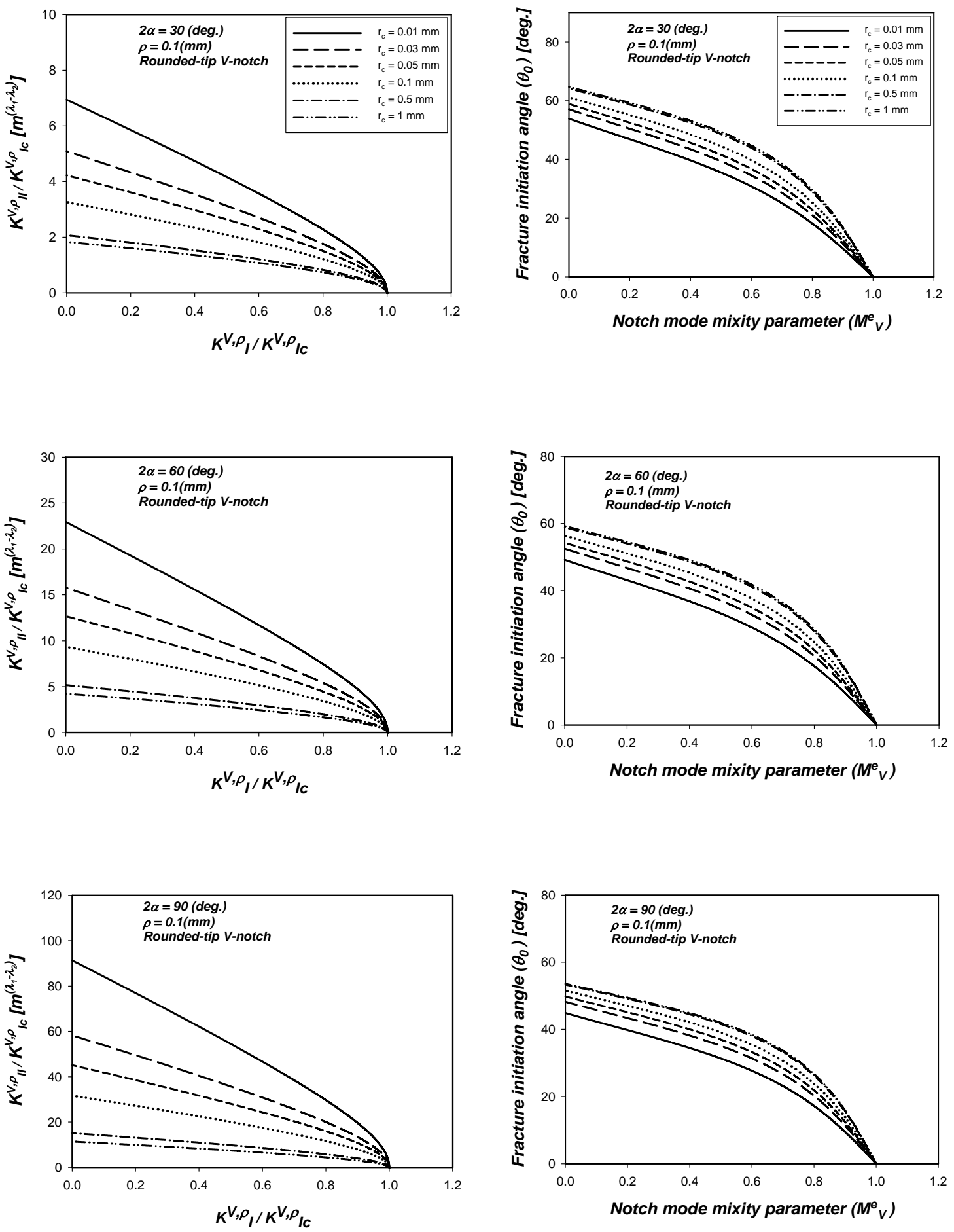

Fig. 6. Mixed mode failure curves for $\rho=0.1 \mathrm{~mm}$. The left and the right columns correspond to the fracture curves and the curves of fracture initiation angle, respectively 

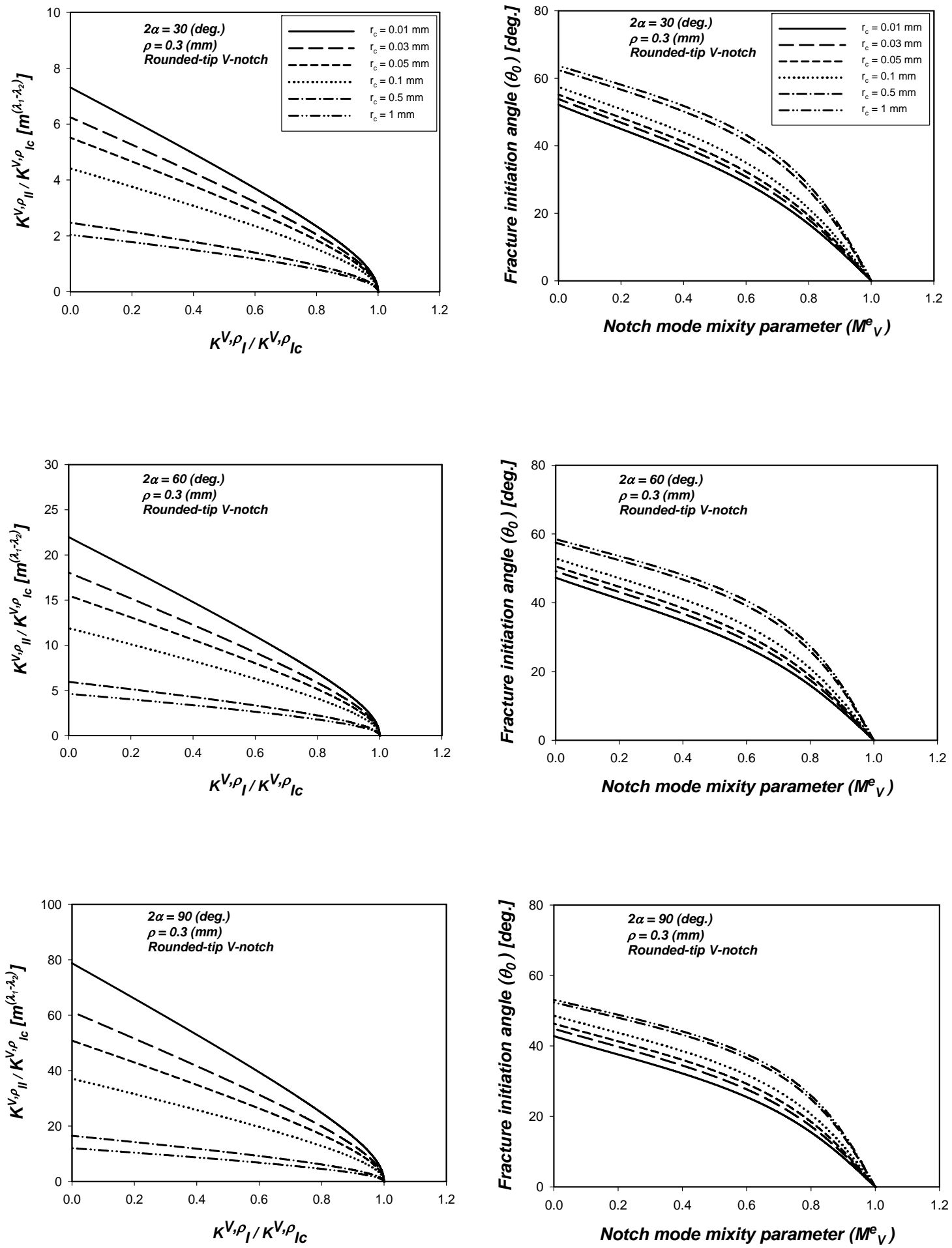

Fig. 7. Mixed mode failure curves for $\rho=0.3 \mathrm{~mm}$. The left and the right columns correspond to the fracture curves and the curves of fracture initiation angle, respectively 

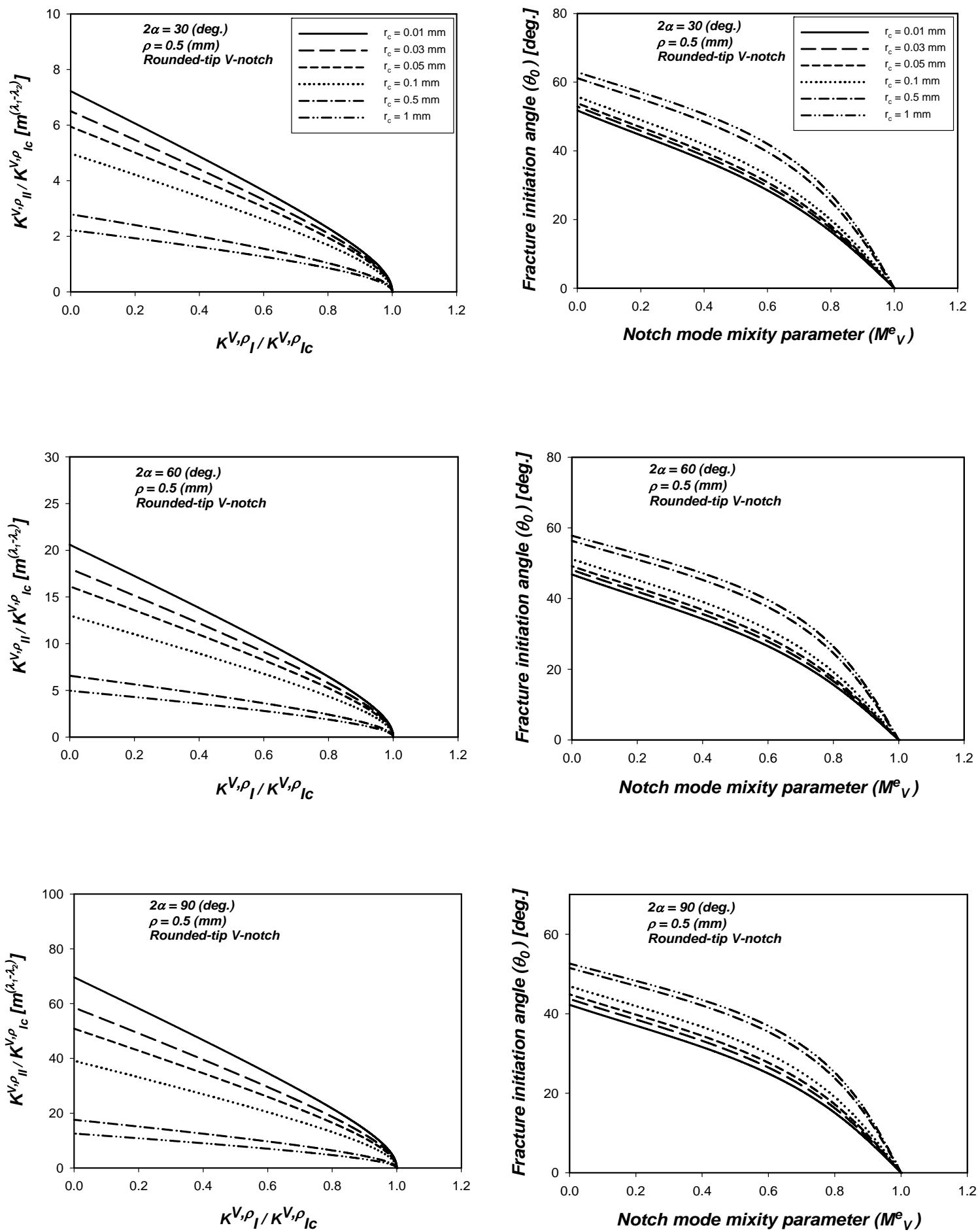

Fig. 8. Mixed mode failure curves for $\rho=0.5 \mathrm{~mm}$. The left and the right columns correspond to the fracture curves and the curves of fracture initiation angle, respectively 

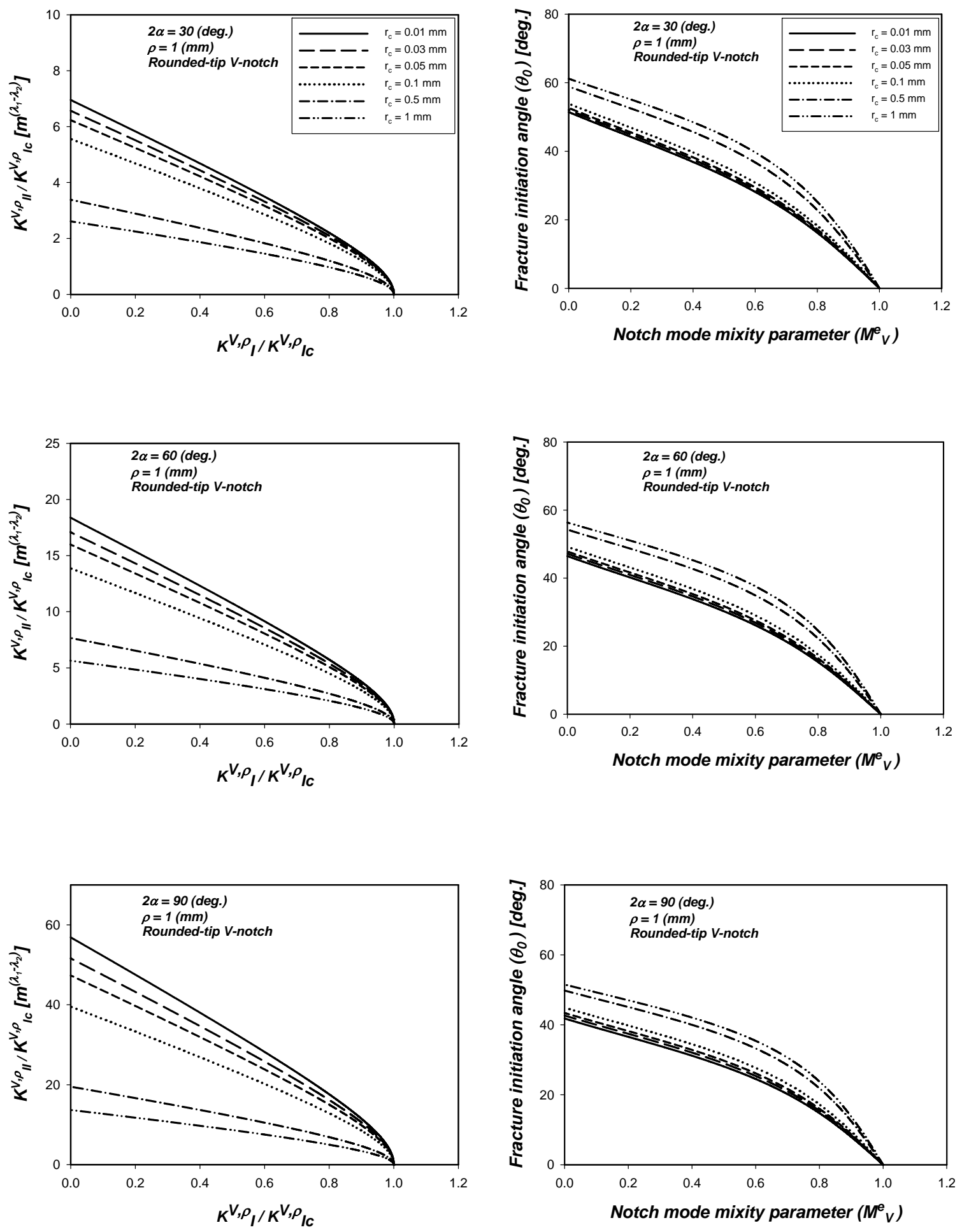

Fig. 9. Mixed mode failure curves for $\rho=1 \mathrm{~mm}$. The left and the right columns correspond to the fracture curves and the curves of fracture initiation angle, respectively 

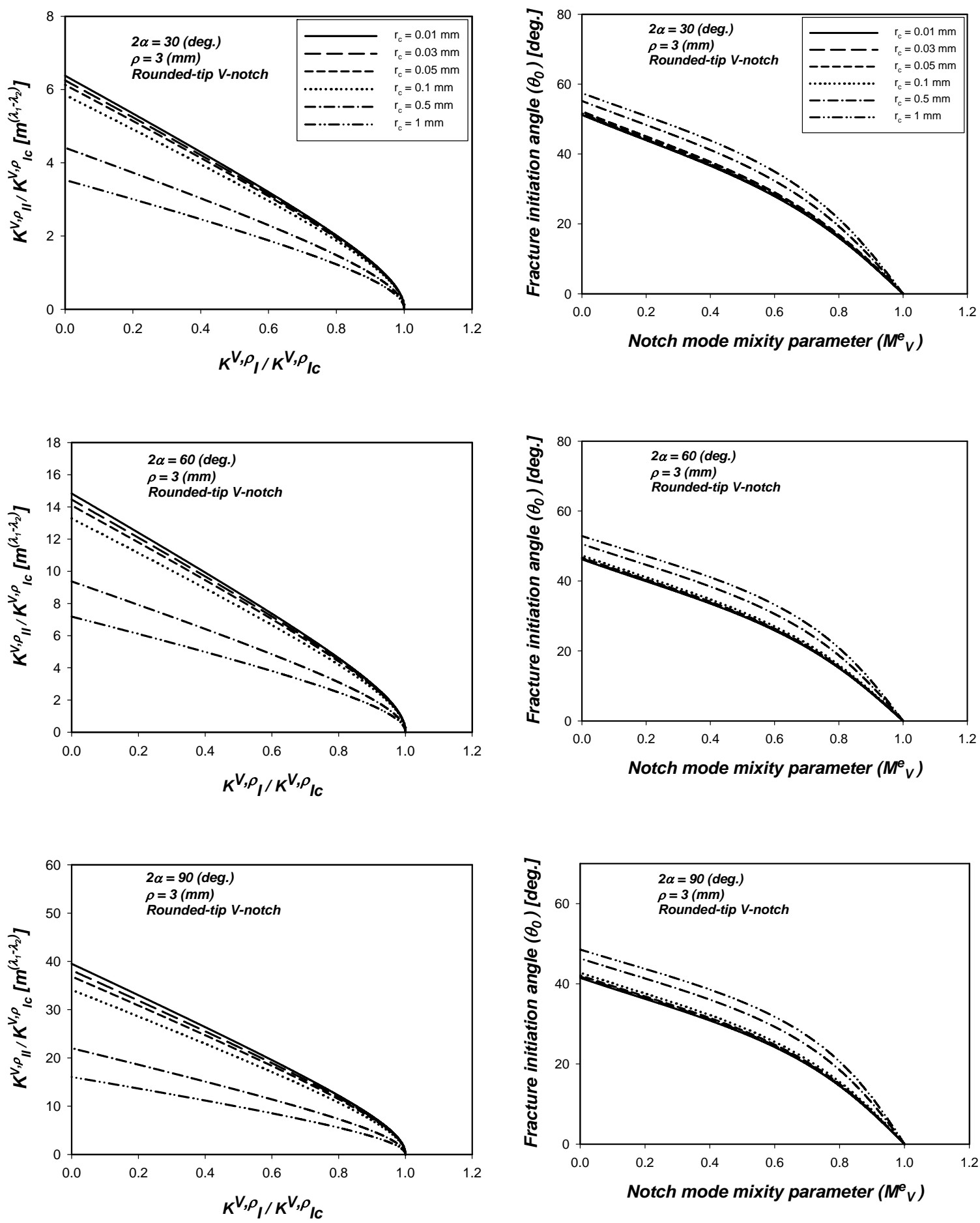

Fig. 10. Mixed mode failure curves for $\rho=3 \mathrm{~mm}$. The left and the right columns correspond to the fracture curves and the curves of fracture initiation angle, respectively 

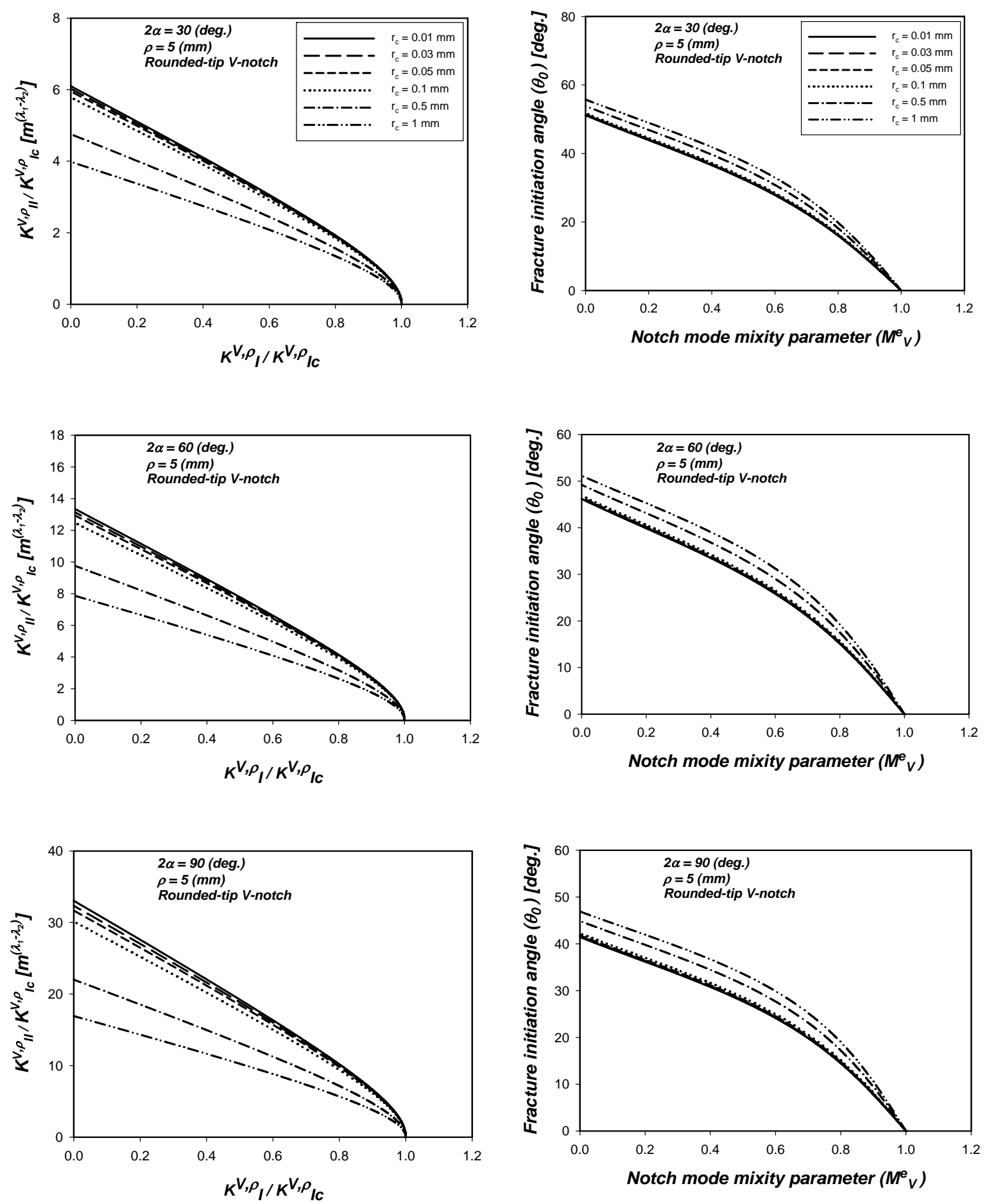

Fig. 11. Mixed mode failure curves for $\rho=5 \mathrm{~mm}$. The left and the right columns correspond to the fracture curves and the curves of fracture initiation angle, respectively 

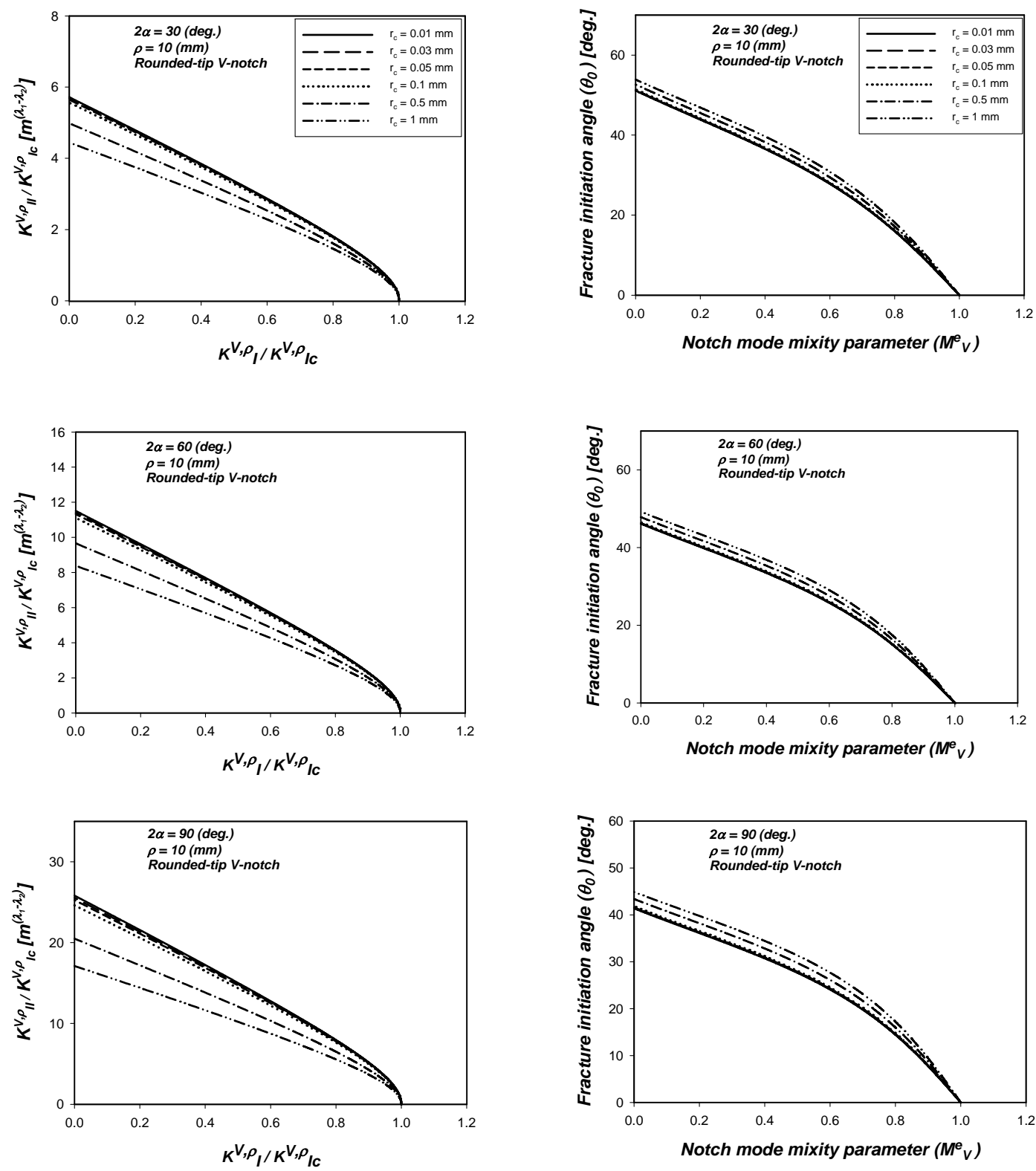

Fig. 12. Mixed mode failure curves for $\rho=10 \mathrm{~mm}$. The left and the right columns correspond to the fracture curves and the curves of fracture initiation angle, respectively

It is important to notice that the curves presented above are recognized by their $r_{c}$ values. Therefore, one should first calculate $r_{c}=\frac{1}{2 \pi}\left(\frac{K_{I c}}{\sigma_{c}}\right)^{2}$ for the brittle material and then select the corresponding failure curves. Although Figs. 4 to 12 are clear enough to obtain the results, some of the main results can be listed as follows:

1. For the entire values of the notch angle and the notch tip radius, as $r_{c}$ enhances, the fracture curves and the curves of fracture initiation angle travel downward and upward, respectively.

2. For sharp V-notches (i.e. $\rho=0 \mathrm{~mm}$ ), $r_{c}$ has no effect on the fracture initiation angle.

3. For sharp $\mathrm{V}$-notches, the fracture initiation angle decreases slightly as the notch angle increases.

4. Generally, for a constant notch angle, the effects of $r_{c}$ on the fracture initiation angle increases as the notch tip radius enhances. 
5. For $\rho=0.01 \mathrm{~mm}$, as the notch angle increases, the sensitivity of the curves of fracture initiation angle (i.e. the distance between the extreme curves in each graph) to $r_{c}$ decreases. For $r_{c}$ values larger than about $0.03 \mathrm{~mm}$, such sensitivity is null.

6. For constant values of $r_{c}$ and $2 \alpha$, as $\rho$ enhances from zero to $1 \mathrm{~mm}$, the fracture initiation angle decreases and for $\rho$ values larger than 1 , it becomes approximately invariant.

7. For a constant notch tip radius, the fracture initiation angle decreases as the notch angle increases.

8. For a constant notch tip radius, as the notch angle increases, the sensitivity of the fracture curves to $r_{c}$ increases.

9. For a constant notch angle and for the notch tip radii larger than $3 \mathrm{~mm}$, the enhancement of $r_{c}$ from 0.01 up to $0.1 \mathrm{~mm}$ has not considerable effects on the fracture curves, particularly for mode I dominant loading conditions. Also, such effects on the curves of fracture initiation angle are almost negligible. It is necessary to highlight that the failure curves presented in this manuscript are valid only in a K-dominant region at the notch tip vicinity, since the stresses around the V-notch tip utilized for developing the curves were characterized only by the NSIFs.

\section{Conclusions}

A compact and comprehensive engineering design package was developed for estimating the loadbearing capacity and the fracture initiation angle (i.e. the notch bifurcation angle) of V-notched components made of brittle materials and loaded under mixed mode I/II loading. The package was resulted based on the reliable and convenient MTS failure concept and covers a wide range of notch angles, notch tip radii and brittle materials. The failure curves presented in this manuscript are effective only when the critical distance of the brittle material $r_{c}$ lies on a $K$-dominant region around the notch tip. Otherwise, the higher order term(s) of the notch stress field may be needed to develop the effective curves. Using the curves, one can design more rapidly and conveniently the brittle structural components weakened by a V-notch without requiring formulating brittle fracture criteria.

\section{Appendix}

The mode I notch fracture toughness $K_{I c}^{V, \rho}$ can be theoretically predicted by using some appropriate fracture criteria such as the point stress (PS) criterion (Ayatollahi \& Torabi, 2010a). The PS model is in fact, the MTS model in pure mode I loading conditions. The PS closed-form expression for $K_{I c}^{V, \rho}$ is

$K_{I c}^{V, \rho}=\frac{\sqrt{2 \pi}\left(\sigma_{\theta \theta}\right)_{c}\left(r_{0}+r_{c}\right)^{1-\lambda_{1}}}{\left(1+\left(1+\frac{r_{c}}{r_{0}}\right)^{\mu_{1}-\lambda_{1}} n_{\theta \theta}(0)\right)}$ and all of the parameters in the expression have been defined by

Ayatollahi and Torabi (2010a).

\section{References}

Aliha, M. R. M., Ayatollahi, M. R., \& Pakzad, R. (2008). Brittle fracture analysis using a ring-shape specimen containing two angled cracks. International Journal of Fracture, 153(1), 63-68.

Ayatollahi, M. R., \& Aliha, M. R. M. (2008). Mixed mode fracture analysis of polycrystalline graphite-a modified MTS criterion. Carbon, 46(10), 1302-1308.

Ayatollahi, M. R., \& Aliha, M. R. M. (2009). Mixed mode fracture in soda lime glass analyzed by using the generalized MTS criterion. International Journal of Solids and Structures, 46(2), 311-321.

Ayatollahi, M. R., \& Aliha, M. R. M. (2011). Fracture analysis of some ceramics under mixed mode loading. Journal of the American Ceramic Society,94(2), 561-569.

Ayatollahi, M. R., Berto, F., \& Lazzarin, P. (2011a). Mixed mode brittle fracture of sharp and blunt V-notches in polycrystalline graphite. Carbon, 49(7), 2465-2474.

Ayatollahi, M. R., Torabi, A. R., \& Azizi, P. (2011b). Experimental and theoretical assessment of brittle fracture in engineering components containing a sharp V-notch. Experimental mechanics, 51(6), 919-932. 
Ayatollahi, M. R., Aliha, M. R. M., \& Saghafi, H. (2011c). An improved semi-circular bend specimen for investigating mixed mode brittle fracture. Engineering Fracture Mechanics, 78(1), 110-123.

Ayatollahi, M. R., \& Torabi, A. R. (2010a). Brittle fracture in rounded-tip V-shaped notches. Materials \& Design, 31(1), 60-67.

Ayatollahi, M. R., \& Torabi, A. R. (2010b). Investigation of mixed mode brittle fracture in rounded-tip Vnotched components. Engineering Fracture Mechanics, 77(16), 3087-3104.

Ayatollahi, M. R., Torabi, A. R., \& Azizi, P. (2011b). Experimental and theoretical assessment of brittle fracture in engineering components containing a sharp V-notch. Experimental mechanics, 51(6), 919-932.

Ayatollahi, M. R., \& Torabi, A. R. (2011a). Failure assessment of notched polycrystalline graphite under tensile-shear loading. Materials Science and Engineering: A, 528(18), 5685-5695.

Ayatollahi, M. R., \& Torabi, A. R. (2011b). Experimental verification of RV-MTS model for fracture in sodalime glass weakened by a V-notch. Journal of mechanical science and technology, 25(10), 2529-2534.

Berto, F., \& Lazzarin, P. (2009a). A review of the volume-based strain energy density approach applied to Vnotches and welded structures. Theoretical and Applied Fracture Mechanics, 52(3), 183-194.

Berto, F., Lazzarin, P., \& Radaj, D. (2009). Fictitious notch rounding concept applied to sharp V-notches: Evaluation of the microstructural support factor for different failure hypotheses: Part II: Microstructural support analysis. Engineering Fracture Mechanics, 76(9), 1151-1175.

Berto, F., Lazzarin, P. \& Radaj, D. (2008). Fictitious notch rounding concept applied to sharp V-notches: Evaluation of the micro structural support factor for different failure hypotheses. Part I: Basic stress equations. Engineering Fracture Mechanics, 75, 3060-3072.

Erdogan, F., \& Sih, G. C. (1963). On the crack extension in plates under plane loading and transverse shear. Journal of basic engineering, 85, 519.

Filippi, S., Lazzarin, P., \& Tovo, R. (2002). Developments of some explicit formulas useful to describe elastic stress fields ahead of notches in plates. International Journal of Solids and Structures, 39(17), 4543-4565.

Gómez, F. J., Elices, M., Berto, F., \& Lazzarin, P. (2009). Fracture of V-notched specimens under mixed mode (I+ II) loading in brittle materials. International journal of fracture, 159(2), 121-135.

Gómez, F. J., \& Elices, M. (2003a). Fracture of components with V-shaped notches. Engineering fracture mechanics, 70(14), 1913-1927.

Gómez, F. J., \& Elices, M. (2003b). A fracture criterion for sharp V-notched samples. International Journal of Fracture, 123(3-4), 163-175.

Gómez, F. J., \& Elices, M. (2004). A fracture criterion for blunted V-notched samples. International Journal of Fracture, 127(3), 239-264.

Lazzarin, P., \& Filippi, S. (2006). A generalized stress intensity factor to be applied to rounded V-shaped notches. International journal of solids and structures, 43(9), 2461-2478.

Lazzarin, P. and Zambardi, R. (2002). The Equivalent Strain Energy Density approach reformulated and applied to sharp V-shaped notches under localised and generalised plasticity. Fatigue and Fracture of Engineering Materials and Structures, 25, 917-928.

Lazzarin, P., \& Zambardi, R. (2001). A finite-volume-energy based approach to predict the static and fatigue behavior of components with sharp V-shaped notches. International Journal of Fracture, 112(3), 275-298.

Leguillon, D., \& Yosibash, Z. (2003). Crack onset at a v-notch. Influence of the notch tip radius. International journal of fracture, 122(1-2), 1-21.

Priel, E., Bussiba, A., Gilad, I., \& Yosibash, Z. (2007). Mixed mode failure criteria for brittle elastic V-notched structures. International journal of fracture, 144(4), 247-265.

Seweryn, A. (1994). Brittle fracture criterion for structures with sharp notches. Engineering Fracture Mechanics, 47(5), 673-681.

Smith, D. J., Ayatollahi, M. R., \& Pavier, M. J. (2001). The role of T-stress in brittle fracture for linear elastic materials under mixed-mode loading. Fatigue \& Fracture of Engineering Materials \& Structures, 24(2), 137-150.

Torabi, A. R. (2013). Wide range brittle fracture curves for U-notched components based on UMTS model. Engineering Solid Mechanics,1(2), 21-33.

Williams, M. L. (1952). Stress singularities resulting from various boundary conditions in angular corners of plates in extension. Journal of Applied Mechanics, 19(4), 526-528.

Yosibash, Z., Priel, E., \& Leguillon, D. (2006). A failure criterion for brittle elastic materials under mixedmode loading. International journal of fracture, 141(1-2), 291-312. 